\title{
Marco general de la competencia $y$ cooperación procesal penal internacional ${ }^{*}$
}

\author{
Jorge Alberto Silva**
}

Recibido: mayo de 2016

Aprobado: octubre de 2016

DOI: 10.22395/ojum.v15n30a3

\section{RESUMEN}

El autor llama la atención sobre algunos elementos de derecho internacional acogidos en la codificación procesal penal mexicana. Presenta la temática relacionada con la competencia judicial internacional, el orden jurídico regulador de los problemas de tráfico jurídico internacional, la cooperación internacional en el nuevo Código Nacional de Procedimientos Penales, incluido el reconocimiento de decisiones extranjeras, la extradición, así como la asistencia consular.

Palabras clave: competencia penal internacional; cooperación judicial internacional; reconocimiento de sentencias penales; extradición; asistencia consular.

Artículo forma parte de un trabajo de investigación mayor, propia del autor y en curso, apoyado por la Universidad Autónoma de Ciudad Juárez, que se encamina a presentar la dogmática jurídica procesal prevista en las nuevas leyes procesales mexicanas que entraron en vigor a mediados de 2016.

* Licenciado y doctor en derecho por la Universidad Autónoma de México, presidente de la Asociación Mexicana de Profesores de Derecho Internacional Privado. Universidad Autónoma de México. Investigador nacional del Consejo Nacional de Ciencia y Tecnología. Área de investigación: derecho internacional. Correo electrónico: silvasi@aol.com 


\title{
General Framework of Competence and International Criminal Procedural Cooperation
}

\begin{abstract}
The author specifically highlights some elements of the international law adopted by the Mexican Criminal Procedural Code. The article shows the topic relating to international judicial competence, the legal system governing issues of international juridical trafficking, and international cooperation in the new National Criminal Procedural Code, including the recognition of foreign decisions, extradition, and consular assistance.
\end{abstract}

Key words: international criminal competence; international judicial cooperation; recognition of criminal sentences; extradition; consular assistance. 


\section{INTRODUCCIÓN}

El objetivo a que se orienta este artículo consiste en explicar la normativa general reguladora de los problemas de tráfico jurídico internacional en las leyes mexicanas; en forma específica, la normativa de fuente interna.

Deriva de un trabajo inicialmente exploratorio con el fin de conocer la normativa que entró en vigor desde mediados de 2016, especialmente, con la finalidad de conocer si la nueva legislación de fuente interna responde a los acuerdos internacionales signados por México. A diferencia de lo habido en la codificación que dejó de estar en vigor, la nueva contempla algunos elementos propios del tráfico jurídico internacional, que cabe destacar.

Como trabajo de investigación exploratoria, mi objetivo consistió en precisar qué es lo que el nuevo orden jurídico procesal penal mexicano comprende, sin dejar de contrastarlo con lo habido en la legislación anterior, en especial, observar y tomar en cuenta la recepción de los convenios internacionales incorporados al derecho de fuente interna. Ciertamente las autoridades deben tomar en cuenta lo prescrito en los tratados, incluso realizar el control de convencionalidad, pero el tema central está dirigido a conocer la normativa de fuente interna.

El objetivo principal consiste en recoger diversos elementos de derecho internacional acogidos en la normativa procesal penal mexicana de fuente interna. Procuro atender al nuevo Código Nacional de Pro- cedimientos Penales (CNPP), entre otras leyes, dado lo novedoso en el derecho de fuente interna mexicana, incluyendo algunas disposiciones que continúan en vigor. Incluyo el orden jurídico regulador de los actos procesales, la competencia en el conocimiento, la cooperación judicial internacional, así como el reconocimiento y ejecución de resoluciones penales extranjeras. La perspectiva metodológica y epistemológica desde la que observo esta regulación es la propia del tráfico jurídico internacional, no los problemas de tráfico jurídico interno. Aunque no hay mucho de doctrina sobre el tema, he tomado en cuenta los datos o elementos que sirvieron de apoyo a las nuevas leyes, sobre todo, los debates y proyectos que provienen de 2008, al igual que los pocos precedentes judiciales habidos.

En el caso del CNPP no hubo Exposición de Motivos, sino que el legislador conformó una serie de tablas, elaboradas por cada partido político. La investigación toma en cuenta los antecedentes habidos con anterioridad, así como lo poco de doctrina publicada, y el objeto de conocimiento es todo lo relacionado con los problemas de tráfico jurídico internacional, desde la perspectiva del derecho de fuente interna. En general, se trata de una temática nueva en el derecho mexicano.

El orden o sistematización que abordo comprende, como regla general, los enunciados legales, continúo con las cuestiones de competencia internacional, que antes no eran tomadas en cuenta; sigo con la cooperación internacional, tanto para solicitar cooperación a un tribunal 
extranjero, como para otorgarla. Por separado, incluyo los problemas relacionados con el reconocimiento y ejecución de sentencias penales extranjeras, y de otros actos; aquí cubro parte de la extradición $\mathrm{y}$, en especial, lo relacionado con la llamada asistencia consular, y termino con conclusiones generales.

Unos de los hechos observados en la experiencia con los jueces mexicanos es que estos consultan las leyes de fuente interna y raramente lo previsto en el derecho convencional internacional. Posiblemente esto se deba a una ausencia de compilaciones de tratados, textos de este tipo, así como una grave ausencia de obras doctrinarias relacionadas con la normativa procesal internacional en el ámbito penal. Normalmente, México ha afrontado la problemática jurídica internacional a partir de tratados, no de derecho interno. Aunque es paupérrima la normativa procesal reguladora de problemas de tráfico jurídico internacional, algunas disposiciones acogen algunas prescripciones sobre el particular, apartado que trato de dar a conocer.

Lo que pretendo es dar a conocer, a partir de un enfoque exploratorio, el panorama que presenta la nueva codificación. Al lado de lo que suelen prever los tratados, ¿con qué se cuenta en el derecho mexicano de fuente interna para este tipo de problemas?

\section{ANTECEDENTES}

No hay que olvidar que el derecho procesal penal mexicano vigente y de fuente interna carecía de disposiciones sobre tráfico jurídico internacional. Las nuevas prescripciones contienen algunas disposiciones novedosas. Originalmente el derecho procesal penal se creó como un instrumento para organizar la represión a través del Estado. Era estudiado en un ámbito y perspectiva normativa muy localista, lo que pudiera haber parecido natural debido a su carácter exclusivista tradicional, en el que no tenían intervención alguna los extranjeros. Se solía pensar que todo Estado tenía la prerrogativa del uso institucional de la violencia, que en principio solo podía darse dentro de sus límites territoriales, perspectiva que ha cambiado en la actualidad, al ampliarse las fronteras.

El hecho es que con frecuencia encontramos que ciertas conductas se producen en el territorio de un Estado y producen consecuencia en otro; que algún delincuente se sustrae a la acción de la justicia de su país, huyendo a otro, llevando a cada uno de los Estados a la necesidad de procurarse cooperación entre ellos con el fin de que sus resoluciones puedan ejecutarse.

Como decía, hay mayor riqueza normativa en el derecho convencional internacional que en el de fuente interna. Solo recordaré que desde el siglo XIX se comenzó a hablar de un derecho penal internacional, propio del derecho convencional. En América del Sur se aprobaron los tratados de Lima y de Montevideo y, luego, en La Habana otro tratado en 1928 (Convención de Derecho Internacional Privado), al que le siguió uno más en Montevideo en 1940 
(Tratado de Derecho Penal Internacional, 1940), en los que se introdujeron algunas prescripciones sobre la materia penal y sobre cooperación judicial internacional (Tratado de Derecho Penal Internacional, 1889). Al paso del tiempo, poco a poco se ha tenido que ir reglamentando estos apartados, pero la doctrina que se ha desarrollado en México ha sido escasa. En la quinta Conferencia Interamericana de Derecho Internacional Privado (CIDIP) surgió la Convención Interamericana sobre Tráfico Internacional de Menores (1994), cuyo capítulo II se refiere a los aspectos penales y de cooperación. Otros convenios y tratados han venido al paso del tiempo, como ya lo referiré.

Actualmente la problemática internacional es intensa. En un mundo globalizado como el actual se producen con mayor frecuencia e intensidad actos ilícitos que tienden a producir efectos fuera de los límites territoriales de los Estados donde se realizan, pero, sobre todo, que requieren de la cooperación de cada Estado de la comunidad internacional. Regulaciones de fuente interna y convencional internacional suelen regular los llamados "problemas de tráfico jurídico internacional".

Durante mucho tiempo, este tipo de problemas fue explicado por el derecho internacional privado. Varias obras de esta disciplina abordaron esta problemática. Actualmente, los privatistas han venido sosteniendo que este capítulo no les corresponde, sino a los encargados del derecho internacional público. El nuevo Código Nacional de Procedimientos Penales incluye un apartado que denomi- na asistencia judicial internacional, así como otras prescripciones relacionadas con el reconocimiento del derecho extranjero, propios del derecho conflictual penal internacional. La toma en consideración de estos nuevos supuestos normativos corresponde a un apartado novedoso en el derecho de fuente interna.

\section{ORDEN JURIDICO REGULADOR DEL PROCESO}

Uno de los temas propios del derecho internacional ha sido la llamada competencia legislativa internacional, es decir, cuál es el orden jurídico que ha de regular cada problema de tráfico jurídico internacional. Generalmente las prescripciones procesales penales que regulan problemas de tráfico jurídico internacional se encuentran en el derecho de fuente interna, aunque en los últimos años se han ampliado al derecho convencional internacional. Esto es, la fuente puede ser de derecho interno o de derecho convencional internacional. Mi objetivo en este apartado se relaciona, de manera general, con la normativa de fuente interna. ¿Pueden los jueces penales tomar en cuenta normativa extranjera?

Cabe una aclaración. La expresión supuesto de tráfico jurídico internacional es propia del metalenguaje y es empleada por los internacionalistas. Lingüísticamente se le atribuye un significado específico respecto del lenguaje objeto. El comportamiento humano o conducta que ese supuesto comprende puede constituirse o iniciarse bajo el ámbito territorial de un orden jurídico y continuar o producir efecto jurídico bajo el ámbito territorial de otro orden (verbigracia, se compra marihuana en un 
país donde es lícita su venta y es llevada a otro, en donde no solo está prohibida, sino que es estimada como delito). La importancia de este supuesto (la compra) supone, en un primer momento, una cuestión: duda respecto a cuál orden regula ese supuesto y lo califica.

La afirmación de que el tráfico es jurídico presupone que las personas, mercancías, cosas, han estado cambiando de lugar, que la conducta o supuesto fáctico se ha desplegado o extendido de uno a otro lugar, donde priva otro orden jurídico. Lo anterior plantea problemas a ser definidos desde la perspectiva jurídica (en forma prescriptiva y descriptiva). Cuando un legislador aborda este tipo de problemas decimos que la prescripción que impone "tiene vocación internacional". Esto es, no contempla exclusivamente lo ocurrido en el interior del propio territorio, pues "va más allá".

Algunas disposiciones abordan esta problemática de tráfico jurídico. Aunque referido a los derechos humanos, el artículo $1 .^{\circ}$ de la Constitución Política de los Estados Unidos Mexicanos (CPEUM) tiene en cuenta todos los tratados sobre derechos humanos que impactan en el derecho procesal. A la vez, el CNPP contempla diversas disposiciones que tienen vocación hacia su internacionalización, fenómeno que se ha acelerado como consecuencia de los procesos de globalización y de la agilización de las comunicaciones. Esta disposición de fuente interna suele referirse a problemas de tráfico jurídico internacional; comprende varias prescripciones sobre el orden jurídico regulador, competencia judicial, inmunidad diplomática, cooperación judicial internacional, medidas cautelares, etc. Por un lado, se reconocen los principios derivados de tratados internacionales (artículos 1, 4, $11,12,18,287,365$, fracc. III, 455, CNPP), y se obliga al respeto a los derechos humanos derivados del derecho convencional internacional (arts. 2, 64, fracc. V, 97, 109, 131, fracc. I, 214, 482, CNPP). En sentido similar, se encuentra el artículo 3 de la Ley de Extradición Internacional y otras más, que complementan la regulación mexicana.

En el derecho de fuente convencional internacional México ha ratificado varios tratados de los que derivan normas materiales uniformes e, incluso, normas que fijan el ámbito espacial de validez de las normas estatales. Entre los tratados encontramos algunos relacionados con la ejecución de sentencias penales, la extradición de procesados y delincuentes, la cooperación para combatir el narcotráfico y el terrorismo, la represión de la tortura, el secuestro de naves aéreas y marítimas, derechos humanos, así como la asistencia jurídica. En realidad, sería imposible referirme a cada uno de estos convenios en un espacio tan reducido, pues solo me contento con listar algunos. Francisco Dondé Matute clasifica algunos de los tratados y menciona, entre ellos, aquellos relacionados con extradición y con asistencia jurídica; algunos bilaterales, otros, multilaterales (Dondé, Cooperación internacional en materia penal, pp. 32 y ss.).

Cabe enfatizar en algunas reglas sobre el orden jurídico regulador estudiado en el 
derecho conflictual internacional. Como regla general, la reglamentación procesal penal mexicana es territorial o exclusivista. Aunque predomina la lex fori, existen hipótesis en el Código, conforme a las cuales el aplicador del derecho debe tomar en consideración, incluso incorporar, ciertos actos, leyes y decisiones penales extranjeras al orden jurídico mexicano, esto es, reconocerlos y llevarlos a su ejecución.

Así, las pruebas y cualquier acto realizado en el extranjero se rigen por la ley extranjera (yo diría, se incorporan al orden jurídico mexicano), lo que significa que el juez mexicano debe tomar en cuenta (recibir) el derecho extranjero acorde con lo prescrito en el derecho conflictual internacional (Silva, Aplicación, p. 28). Los tribunales judiciales desde hace tiempo así lo han admitido, al resolver que:

[...] las pruebas desahogadas en el extranjero por órganos o autoridades distintos merecen valor demostrativo en los casos siguientes: 1. Cuando se acredite que fueron obtenidas de acuerdo con las reglas que dispone el sistema jurídico nacional, por ejemplo: a) en los casos en que las pruebas se requieren por autoridades mexicanas a las competentes del Estado extranjero, se recaban por éstas y se remiten a nuestro país, en observancia a los instrumentos jurídicos internacionales suscritos por México en materia de cooperación y asistencia jurídica mutua; b) las pruebas, independientemente de haberse requerido o no, se desahogan en el extranjero por autoridades mexicanas con facultades para hacerlo, [...]; o 2. Cuan- do se acredite que las pruebas se obtuvieron conforme a las reglas procesales que rigen en el país de origen, lo que necesariamente demanda que el derecho extranjero se demuestre dentro del procedimiento penal mexicano, es decir, su existencia, aplicabilidad, y correlativa traducción al idioma español; supuesto que se justifica en la medida en que constituye un parámetro eficaz que permite a los juzgadores nacionales evaluar si esos medios de prueba se recabaron de manera lícita y acorde con las disposiciones legales que regulan su desahogo, lo que no sólo es congruente con la doctrina jurisprudencial sustentada por la Suprema Corte de Justicia de la Nación en materia de licitud de pruebas y con el principio generalmente aceptado de que los actos jurídicos se rigen por la ley del lugar en que se celebraron o tuvieron lugar, sino con la obligación constitucional de respetar el debido proceso en toda instancia judicial (Silva, Aplicación, p. 36) (Suprema Corte de Justicia de la Nación, AD 2/2010, 27 de mayo de 2010, unanimidad de votos, registro: 161020).

Desgraciadamente en el ámbito procesal penal, a diferencia del civil, familiar y comercial, no se dispone de textos claros para que el juez pueda conocer el derecho extranjero y determinar con mayor transparencia cuándo ha de tomarlo en cuenta y cuándo no, esto es, me refiero a la competencia legislativa internacional. Es posible que esto se deba a la novedad, pues con anterioridad no se hacía alusión a esta parte del derecho penal internacional. Veamos un ejemplo: 
Ejemplo: un par de turistas iraníes que estaban de vacaciones en México dieron a luz a un hijo (en suelo mexicano). Tan pronto como la señora se recuperó, regresaron a su país. Al paso de los años, aquel niño creció y se casó en tres ocasiones sin disolver algún matrimonio. En Irán es permisible el matrimonio polígamo para quienes profesan la religión islámica. Un buen día aquel hombre decide conocer México, lugar donde nació, acompañado de sus tres mujeres. Alguien avisó que un bígamo se paseaba por la ciudad y fue detenido y consignado. El juez debe resolver si ese hombre debe ser o no sancionado penalmente. Por un lado, el juez se enfrentará entre conocer el derecho extranjero y, por otro, a una prescripción del Código Penal que sanciona "el delito" cometido en el extranjero. ¿Cómo demostrar que esa conducta es o no delito en el extranjero? Indudablemente para resolver lo anterior se requiere de cierto conocimiento del derecho conflictual, que no está desarrollado en la legislación procesal penal mexicana, así como de los tratados sobre derechos humanos que reconocen los actos del estado civil sin que importe nacionalidad ni domicilio.

Acorde al llamado principio de territorialidad o exclusividad de la ley, será la ley mexicana la que se aplicará por las autoridades mexicanas (es la tesis dominante). En el derecho sustantivo, incluso, se acoge la lex loci commissi delicti, siguiéndose normalmente que las leyes y actos extranjeros no tendrán aplicación alguna en México. Es decir, se sigue la legis non obligat extraterritorium (sentido negativo).
Cabe, no obstante, admitir ciertas excepciones derivadas de la misma ley interna y de tratados internacionales, que permiten reconocer y aceptar actos y resoluciones extranjeras.

En el año 2005 un tribunal colegiado mexicano resolvió el caso de un extranjero que llegó a México portando un arma (en México es delito portar armas), por lo que fue detenido. Adujo en su defensa que portarla es un derecho en su país, argumentando a su favor un "error invencible cumplir con la ley mexicana", pues no conocía el derecho mexicano. El tribunal resolvió que, en todo caso, debía haber probado el contenido del derecho extranjero, pero también introdujo algunos elementos de interés:

Cuando el inculpado alega que cometió el delito de portación de arma de fuego sin licencia, bajo la creencia de que su conducta se justifica porque en el país de donde proviene, se permite portar armas con la condición de llevarlas descargadas y separadas de sus cargadores, de conformidad con el artículo 15, fracción VIII, inciso B), del Código Penal Federal, cuyo tenor literal es: "El delito se excluye cuando: ... VIII. Se realice la acción o la omisión bajo un error invencible: ... B) Respecto de la licitud de la conducta, ya sea porque el sujeto desconozca la existencia de la ley o el alcance de la misma, o porque crea que está justificada su conducta"; debe en primer lugar demostrar que el derecho de ese país contiene una norma legal que corrobora su argumentación que precisamente lo llevó a caer en el error. Ahora bien, lo anterior no 
contraviene el principio jurídico de que el derecho no está sujeto a prueba, pero tratándose del extranjero, el juzgador nacional no está obligado a conocerlo, de ahí que corra a cargo de las partes su demostración al invocarlo en su favor, en términos de la Convención Interamericana sobre Prueba e Información acerca del Derecho Extranjero, publicada en el Diario Oficial de la Federación el veintinueve de abril de mil novecientos ochenta y tres que en lo que interesa convino: "Artículo 1. La presente convención tiene por objeto establecer normas sobre la cooperación internacional entre los Estados-partes para la obtención de elementos de prueba e información acerca del derecho de cada uno de ellos"; por tanto, si el inculpado hace partir su error de preceptos legales a los que estaba sometido en un país extranjero, los cuales estimó aplicables en territorio mexicano, no basta sólo su invocación sino que debe acreditar su existencia y que contemplan los supuestos en el sentido que alega lo hizo caer en la creencia falsa, de tal suerte que si no ofrece pruebas en torno a ese punto, el juzgador no puede emprender el análisis de la excluyente citada (AD 84/2005, 15 de abril de 2005, unanimidad de votos, registro: 177627).

Un dato de interés en esta resolución fue que el tribunal mexicano reconoció la aplicabilidad de la Convención Interamericana sobre Prueba e Información acerca del Derecho Extranjero, a pesar de que se trató de un asunto penal. En lo que erró el tribunal fue en afirmar que el derecho extranjero lo debe probar el interesado.
Acorde con este convenio internacional, el juez debe aplicar los actos necesarios para conocer el derecho extranjero, pues la Convención acoge el principio iura novit curia, esto es, un conocimiento oficioso. Si acaso el juez lo desconoce, para eso está el tratado, que le dice qué procedimiento debe seguir para conocer el contenido de ese derecho extranjero. Tal vez lo interesante fue el medio por el cual introdujo el argumento relacionado con el error invencible, que no es objeto de este artículo. Lo que destaco con esta resolución es la posibilidad de que el juez mexicano pueda conocer y aplicar lo previsto en el derecho extranjero, algo que no está muy claro en las leyes penales de fuente interna.

\section{COMPETENCIA INTERNACIONAL}

La competencia internacional de los órganos mexicanos, especialmente los relacionados con la acusación (Ministerio Público), el juzgamiento (juzgadores) y la ejecución, ha sido abordada en el derecho de fuente interna con mayor fuerza que en el convencional internacional, aunque este último no desatiende esta temática (Silva, "La competencia judicial, p. 45). Me interesa destacar cómo es que en el derecho de fuente interna mexicano se precisa cuándo las autoridades mexicanas son competentes tratándose de problemas de tráfico jurídico internacional. Para resaltar este apartado aludo a algunos convenios internacionales contra los que cabe la contrastación.

Tradicionalmente, la competencia para conocer de los delitos e investigarlos es la fijada conforme al forum commissi delicti, 
que conduce a una absoluta territorialidad. No obstante, diversos convenios de colaboración internacional han permitido el auxilio de otros países (Silva, La competencia judicial, p. 125).

No hay que olvidar que hoy, más que ayer, la delincuencia desborda las fronteras, que actualmente son más graves los delitos de quienes las cruzan, que lo que ocurrió ayer. Basta recordar únicamente la problemática en que se inmiscuyen las autoridades judiciales para juzgar de delitos de delincuencia organizada trasnacional, tráfico de migrantes, de drogas, etc. Frente a hechos como estos, no cabe continuar afirmando con rabia una territorialidad absoluta (Choclan, p. 232).

El Código de Justicia Militar (modificado recientemente en mayo de 2016) abre la posibilidad de que tribunales mexicanos juzguen un delito cometido en el extranjero, siempre que ello se admita en los tratados internacionales:

Artículo 61. Si el ejército estuviera en territorio de una potencia amiga o neutral, se observarán en cuanto a la competencia de los tribunales, las reglas que estuvieron estipuladas en los tratados o convenciones con esa potencia.

Aunque será difícil la concreción de esta disposición, la cito como hipótesis en que el legislador le imprimió a su texto una "vocación internacional".

En general, la competencia judicial parte del forum commissi delicti. Esto es, que el criterio territorial que aún prevalece en materia penal no solo otorga competencia para los casos en que el delito se cometió en México, sino también cuando el mismo (iniciado en el extranjero) produce efectos en el país. Agréganse a lo anterior aquellos casos de atribución de competencia para conocer de los delitos iuris gentium o "principio de competencia universal". El CNPP prescribe que los tribunales federales serán competentes para conocer de los delitos cometidos en el extranjero (artículos 20, fracc. VIII y 22, fracc. IX).

México se vio envuelto, a finales del siglo XIX, en un problema internacional en el que Estados Unidos de América (EUA) debatió que carecía de competencia para juzgar a un ciudadano de ese país. EUA. La controversia se siguió por la vía diplomática e, incluso, hubo vientos de guerra (Silva, El Caso Cutting).

El tema de la competencia no se ciñe únicamente a conocer quién conocerá y resolverá de una conducta estimada como delictuosa (competencia directa), sino que la competencia internacional también comprende determinar quién es competente para auxiliar y ejecutar decisiones extranjeras, es decir, aquellos casos en que se presenta la cooperación internacional (competencia auxiliar o indirecta).

Conforme a la llamada competencia indirecta es factible que una persona penalmente sentenciada en el extranjero cumpla su condena en México, acto que ejecutarían las autoridades mexicanas, de la misma 
manera en que una persona sentenciada en México puede compurgar su condena en otro país. Sobre el particular, se han celebrado diversos tratados sobre ejecución de sentencias penales, muy poco de lo cual se ha recibido en las leyes de fuente interna.

En cuanto a la competencia judicial para atender y resolver en torno a un delito, la ley mexicana ha sido territorial, lo que impide recurrir a los procedimientos de declinatoria o de inhibitoria. Es decir, ni podrá declinarse a favor de un tribunal extranjero, ni requerirse a un tribunal extranjero que deje de conocer de un asunto. En todo caso, México podrá declararse incompetente, dejando de conocer del asunto, sin enviar documentación alguna al extranjero y sin poder reclamar que del extranjero le remitan los registros conformados.

A propósito de la competencia de los órganos mexicanos cabe enfatizar en la inmunidad diplomática y consular, así como en la competencia por universalidad del delito. Me detengo rápidamente en estos apartados.

\section{Inmunidad diplomática y consular}

En el ámbito procesal es destacado el llamado principio de aplicación personal de la ley, que procura la protección de ciertos súbditos extranjeros (Paz y Puente, p. 48). Aquí no se atiende al lugar de realización de la conducta delictuosa ni a su resultado, sino principalmente a un tipo específico de sujetos (los nacionales de un país) (Matías Récio Juárez, p. 56).
El derecho internacional otorga algunos privilegios a personas específicas que representan a otros Estados. Me refiero a la inmunidad diplomática y consular. Al amparo de esta, según lo indica la Convención de Viena sobre Relaciones Diplomáticas, ningún agente diplomático podrá ser detenido o arrestado (artículo 29). Gozará, además, de inmunidad de jurisdicción penal en el Estado receptor (artículo 31). A la vez, de acuerdo con el CNPP, los extranjeros que gocen en el país de inmunidad diplomática no están obligados a comparecer a las audiencias. Sobre el particular, es poco lo que del derecho convencional internacional se ha aplicado en las leyes de fuente interna.

Lo anterior significa que las personas amparadas en una inmunidad diplomática y consular no podrán ser enjuiciadas por el Estado receptor, ni siquiera obligadas a asistir a alguna audiencia; es decir, la legislación de fuente interna tiende a garantizar la realización de la misión diplomática que se le ha encomendado.

\section{Universalidad jurisdiccional}

Para Adolfo Miaja de la Muela, la inmunidad jurisdiccional "preconiza la competencia de los jueces de todos los Estados para reprimir los hechos causados por el delincuente que es aprehendido en su territorio" (Muela, p. 407).

Según Juan José Díez Sánchez, "este principio relativo de justicia universal tiene como finalidad permitir, sin obstáculo alguno, que ciertas infracciones, 
por diversos motivos, puedan enjuiciarse por cualquier Estado sea cual sea el lugar en que se hayan cometido" (Díez, p. 174).

Aquí están en juego los delicta iuris gentium, esto es, los delitos que se estiman afectan a todos los Estados de la comunidad internacional. Como ejemplos en el derecho alemán encontramos, entre otros, el genocidio, los crímenes de energía nuclear, explosivos y radiación, la agresión al tráfico aéreo, el favorecimiento de la prostitución, la venta indebida de narcóticos, la divulgación de escritos pornográficos y la falsificación de monedas y valores.

El derecho de fuente interna mexicano también acoge una prescripción similar, como podrá observarse del artículo 148 del Código Penal Federal (CPF), que reprime la violación a la inmunidad y a la neutralidad (violar la inmunidad diplomática o la parlamentaria, violar escudos o emblemas de una potencia amiga). Algo semejante se presenta en los casos de falsificación de moneda (artículo 234, CPF), sabotaje (artículo 140, CPF), etcétera.

En el ámbito interno, los tribunales mexicanos han resuelto diversos casos de falsificación de moneda, en los que incluso han calificado como moneda lo que en otros países así es estimado, con lo cual se recurre a una calificación lex causae (Suprema Corte de Justicia de la Nación, AD 2177/85, Fitz Roy Laurence y Manuel Brizuela Vargas o Manuel Romero Aguilar, registro: 233956).

\section{COOPERACIÓN JUDICIAL INTERNACIONAL}

La cooperación o auxilio entre los ór ganos que tienen como misión procurar justicia es una práctica común entre los países. Tal colaboración no se constriñe a la cooperación intraprocesal, sino que se amplía a los órganos encargados de ejecutar sentencias (la actividad posprocesal) (Dondé, Cooperación, p. 87).

En la cooperación internacional deben diferenciarse las hipótesis en que México sea Estado requirente o que sea Estado requerido. Sea que México requiera o al que se le requiera, el orden jurídico doméstico establece algunas prescripciones sobre el particular. Presento enseguida cada una de estas hipótesis acogidas en el derecho de fuente interna.

\section{a. Requerimientos a un estado extranjero}

En el ámbito de su competencia, México prestará a cualquier Estado extranjero que lo requiera la ayuda relacionada con la investigación, el procesamiento y la sanción de delitos. Tal auxilio se prestará acorde con lo que prescriba el orden jurídico mexicano y los tratados en vigor, dentro de la mayor brevedad posible (artículo 433, CNPP).

La solicitud de auxilio a una autoridad extranjera podrá realizarse por medio de exhorto o carta rogatoria judicial o por medio de una comisión consular. En el primer caso, la solicitud se hará a una autoridad judicial extranjera; en el segundo, a un órgano consular mexicano acreditado en el extranjero. Al primero, el CNPP 
(artículo 80) le llama exhorto; al segundo, práctica por medio de oficio:

Los exhortos que se remitan al extranjero serán comunicaciones oficiales escritas que contendrán la petición de realización de las actuaciones necesarias en el procedimiento en que se expidan. Dichas comunicaciones contendrán los datos e información necesaria, las constancias y demás anexos procedentes según sea el caso.

Los exhortos serán transmitidos al órgano jurisdiccional requerido a través de los funcionarios consulares o agentes diplomáticos, o por la autoridad competente del Estado requirente o requerido según sea el caso.

Podrá encomendarse la práctica de diligencias en países extranjeros a los funcionarios consulares de la República por medio de oficio.

La solicitud de cooperación deberá expresar, con claridad, la actuación que ha de practicarse, el nombre del imputado si fuere posible, el delito de que se trate, el número único de causa, así como el fundamento de la providencia y, en caso necesario, el aviso de que se mandará la información.

También cabe la posibilidad de solicitar auxilio al extranjero en el caso de que algún testigo resida en el extranjero, solicitud de prueba anticipada que deberá realizar el juez de control (artículo 304, fracc. II, CNPP).
Para los casos de investigación de conductas delictuosas o localización de infractores, en el ámbito mundial existe una corporación internacional: la Interpol, que realiza actividades de investigación policiaca en diferentes países. En los últimos años una gran cantidad de presuntos delincuentes han sido localizados por medio de esa organización. Por desgracia, este apartado no ha sido reglamentado en la ley de fuente interna.

Más referido a la normativa de fuente interna, pero no como parte del procedimiento penal, la Ley federal para la protección a personas que intervienen en el procedimiento penal se presta para cierto auxilio a las autoridades extranjeras. Por ejemplo, el artículo 42 prescribe: "Para el caso de que se requiera la comparecencia de la persona en algún otro país, ya sea para rendir declaración o para facilitar la investigación de delitos en los que esté involucrado o tenga conocimiento de información relevante para su persecución, la solicitud respectiva se atenderá de conformidad con lo dispuesto en los tratados internacionales en materia penal y demás normas aplicables".

\section{En este caso, agrega:}

En el supuesto de que el testimonio que vaya a rendir la persona en otro país se refiera a delitos en los que haya estado involucrado, el país requirente deberá otorgar la garantía suficiente por vía diplomática de que no detendrá, ni procesará a la persona y que lo regresará a México en cuanto termine de rendir la declaración que le competa, además de otorgar 
las medidas de seguridad que resulten necesarias para preservar su seguridad e integridad.

Resulta, por demás, interesante esta disposición, pues México podrá "prestar" a una persona para que asista a un proceso abierto en el extranjero, pero con la condición de que se lo "regresen".

\section{b. Requerimientos a las autoridades mexicanas}

Seguramente este es un apartado en el que se han incluido nuevas disposiciones en la nueva codificación mexicana, inexistentes con anterioridad. Me refiero a las nuevas: las solicitudes de cooperación que provengan de tribunales extranjeros deberán ser tramitadas de conformidad con lo que prevean los tratados internacionales (artículo 435, CNPP) y, a falta de estos, de acuerdo con lo que prevé el CNPP (título VIII) y, si acaso la solicitud se recibe en idioma extranjero deberá acompañarse su traducción (artículo 78, CNPP).

Toda solicitud proveniente del extranjero -dice la ley- deberá hacerse por medio formal o informal: la formal únicamente es por medio de exhorto (artículo 78, CNPP); la informal por cualquier otro medio que se reducirá a mera o simple información. En este último caso, la información o documentación solo servirá como indicio a la autoridad investigadora, y en ningún caso, podrá formalizarse, a menos que sea requerida mediante la cooperación o asistencia jurídica internacional, cubriendo todos los requisitos señalados en los convenios y tratados (artículo 455).
Todo exhorto o carta rogatoria deberá formularse por escrito, en español y, tratándose de casos urgentes, enviarse por medio de fax, correo electrónico o cualquier otro medio de comunicación permitido, bajo el compromiso de enviar el documento original a la brevedad posible (artículo 441, CNPP). Se trata de lo que en derecho internacional se conoce como anticipación de la carta rogatoria.

Cualquier solicitud de cooperación dirigida a las autoridades mexicanas deberá contener, como requisitos mínimos, los siguientes: identidad de la autoridad que requiere el auxilio; asunto y naturaleza de la investigación, procedimiento o diligencia; una breve descripción de los hechos; propósito para el que se requieren las pruebas; la información o la actuación; métodos de ejecución a seguirse; de ser posible, la identidad, ubicación y nacionalidad de toda persona interesada, y transcripción de las disposiciones legales aplicables (artículo 442, CNPP).

Solo se otorgará auxilio o cooperación a las autoridades extranjeras cuando: lo solicitado esté vinculado a una investigación en curso; se refiera a hechos concretos y la solicitud sea precisa; a cualquier tipo de solicitud, salvo que se trate de medidas de aseguramiento o embargo, cateo o registro domiciliario o decomiso o incautación, en cuyo caso será necesario que el hecho que da lugar al procedimiento sea también considerado como delito por la legislación mexicana, y que exista reciprocidad internacional (artículos 436 y 438, CNPP). 
En este sentido, la información requerida por las autoridades mexicanas es tajante, sin posibilidad de flexibilización, salvo en caso que se refiera a proporcionar la nacionalidad de las personas, a que se alude en la última parte.

En el procedimiento de recepción de exhortos, contamos con una figura jurídica importante (inexistente en el viejo enjuiciamiento): la retransmisión del exhorto, ya establecida en tratados y el Código Federal de Procedimientos Civiles. Así, el artículo 77 del CNPP prescribe:

\begin{abstract}
Cuando un juez de control no pueda dar cumplimiento al exhorto o requisitoria, por hallarse en otra jurisdicción la persona o las cosas que sean objeto de la diligencia, lo remitirá al juez de control del lugar en que aquélla o éstas se encuentren, y lo hará saber al exhortante o requirente dentro de las veinticuatro horas siguientes. Si el juez de control que recibe el exhorto o requisitoria del juzgador originalmente exhortado, resuelve desahogarlo, una vez hecho lo devolverá directamente al exhortante.
\end{abstract}

Si de lo que se trata es de otorgar cooperación, pues que se otorgue, y que no tenga el juez que esperar a que la autoridad extranjera se lo pida, bajo el pretexto de que no le "delegó jurisdicción".

En el derecho internacional privado este mecanismo de retransmisión opera únicamente entre tribunales de un mismo Estado (solo dentro de tribunales mexicanos), no pudiendo operar la retransmi- sión hacia otro Estado de la comunidad internacional. En el ámbito procesal penal opera algo semejante.

Las solicitudes de cooperación se recibirán por medio de la autoridad central mexicana, que en este caso es la Fiscalía General de la República', entidad que ejercerá las atribuciones establecidas en el CNPP o se recibirán a través de la vía diplomática (artículo 437, CNPP). El auxilio o cooperación que podrá otorgarse se referirá a alguno de los siguientes actos (artículo 439, CNPP):

i. Notificación de documentos procesales;

ii. Obtención de pruebas;

iii. Intercambio de información e iniciación de procedimientos penales en la parte requerida;

iv. Localización e identificación de personas y objetos;

v. Recepción de declaraciones y testimonios, así como práctica de dictámenes periciales;

vi. Ejecución de órdenes de cateo o registro domiciliario y demás medidas cautelares; aseguramiento de objetos, productos o instrumentos del delito;

\footnotetext{
En el ámbito civil la autoridad central reside en el jurídico de la Secretaría de Relaciones Exteriores o en los (Desarrollo Integral de la Familia) DIF estatales.
} 
vii. Citación de imputados, testigos, víctimas y peritos para comparecer voluntariamente ante autoridad competente en la parte requirente;

viii. Citación y traslado temporal de personas privadas de libertad en la parte requerida, a fin de comparecer como testigos o víctimas ante la parte requirente, o para otras actuaciones procesales indicadas en la solicitud de asistencia;

ix. Entrega de documentos, objetos y otros medios de prueba;

x. Autorización de la presencia o participación, durante la ejecución de una solicitud de asistencia jurídica de representantes de las autoridades competentes del Estado o autoridad requirente, $\mathrm{y}$

xi. Cualquier otra forma de asistencia, siempre y cuando no esté prohibida por la legislación mexicana.

Al recibirse una solicitud de auxilio o cooperación proveniente del extranjero, y previa revisión de su procedencia, se procurará de inmediato su ejecución, salvo que lo solicitado requiera de homologación (artículo 79, CNPP) o que deba negarse la solicitud. La revisión consiste en constatar que lo solicitado cumple con los requisitos exigidos o se apega a algún tratado internacional vigente (artículo 443, CNPP). La solicitud se admitirá o rechazará. Si se rechaza, deberá informarse de ello al solicitante.
En cualquier caso, las autoridades que tengan conocimiento o participen en la ejecución y desahogo de alguna solicitud de cooperación deberán mantener confidencialidad sobre la misma, así como de los documentos que la sustenten. $\mathrm{Ni}$ la prensa podrá ser enterada de esto, lo que a muchos funcionarios les encanta (artículo 444, CNPP).

La homologación es el reconocimiento de un acto extranjero, que normalmente conduce a incorporarlo al orden mexicano mediante la resolución correspondiente, previo procedimiento de exequatur. Como regla general, no se requerirá de exequatur ni homologación, salvo que el acto a ser ejecutado requiera de "ejecución coactiva sobre personas, bienes o derechos" (artículo 79 CNPP). Se trata de una disposición novedosa en el derecho de fuente interna, que ha sido copiado de la normativa procesal civil, incluso, del derecho internacional privado.

La denegación de una solicitud procederá cuando su ejecución o cumplimiento (artículo 440, CNPP): pueda contravenir la seguridad y el orden público; sea contraria a la legislación nacional; sea contraria a las obligaciones internacionales adquiridas por México; se refiera a delitos del fuero militar; se refiera a un delito que sea considerado de carácter político por el gobierno mexicano; se refiera a un delito sancionado con pena de muerte, a menos que la parte requirente otorgue garantías suficientes de que no se impondrá la pena de muerte o de que, si se impone, no será ejecutada; se refiera a hechos con base en los cuales la persona sujeta a investi- 
gación o a proceso haya sido definitivamente absuelta o condenada por México.

Procederá el aplazamiento de una solicitud de cooperación cuando el cumplimiento de lo solicitado pueda perjudicar u obstaculizar una investigación o procedimiento judicial en curso. Aunque de hecho esto podía ocurrir anteriormente a las reformas, hoy ya se encuentra en la ley.

Sea que se deniegue o difiera el cumplimiento del acto solicitado, la Autoridad Central mexicana deberá informarle al requirente, expresándole los motivos de tal decisión. Se trata de una nueva disposición, ya admitida en el ámbito de lo procesal civil internacional.

Todos los gastos relacionados con el cumplimiento de una solicitud de cooperación internacional correrán por cuenta de México, salvo los honorarios legales de peritos y los relacionados con el traslado de testigos. En este caso, el costo de peritos no corre por cuenta de México, a pesar de la gratuidad a que alude el artículo 103 del CNPP. La Autoridad Central tiene la facultad de determinar, de acuerdo con la naturaleza de la solicitud, aquellos casos en los que no sea posible cubrir el costo de su desahogo, lo que comunicará de inmediato al Estado o a la autoridad requirente para que sufrague los mismos o, en su defecto, decida o no continuar cumplimentando la petición (artículo 454, CNPP). Se trata de una disposición novedosa.

Me llaman la atención ciertos actos realizados en cooperación a jueces estaduni- denses, que no se realizaron precisamente por medio de exhorto; se trata de actos que en otra obra presenté y que aparecen en el CNPP (artículo 22). De ahí transcribo una parte de lo dicho:

En junio de 2007 llamó la atención el hecho de que la Facultad de Derecho de la UNAM auxiliara a un juez en EUA para que fuesen interrogadas algunas personas. Se trató de un caso criminal en donde el acusado, detenido en EUA (Eduardo Rodríguez), requería de la declaración de su familia, que no pudo estar en EUA. Tanto fiscal como defensor interrogaron a estas personas, que fueron citadas a la Sala del Consejo Técnico de la Facultad, por vía de videoconferencia.

Otro caso fue el realizado en la Ciudad de México en el que fue interrogado el cardenal Norberto Rivera Carrera, así como el obispo de Tehuacán (agosto de 2007) para un proceso seguido en California, en el que se acusó a la Iglesia católica de EUA de actos ilegales contra menores (pederastia), teniendo que atestiguar los mexicanos. Este asunto llamó la atención a la prensa, produciéndose declaraciones de organizaciones particulares (Silva, Derecho internacional, p. 632).

Este medio de cooperación internacional cabe dentro de los comisionados particulares (commissioners), un medio utilizado en Estados Unidos y que se emplea en algunos casos de cooperación en materia civil. En el ámbito internacional y en 
la Conferencia de La Haya es diferente a las cartas rogatorias, pero no se encuentra regulado en el derecho de fuente interna.

\section{RECONOCIMIENTO Y EJECUCIÓN DE SENTENCIAS PENALES}

Otro de los temas propios del derecho internacional es el relacionado con el reconocimiento de decisiones extranjeras. Algunos autores lo colocan dentro de del capítulo de la cooperación judicial internacional, otros, prefieren una separación. A este reconocimiento me encamino en las próximas líneas. ¿Cómo es que México reconoce y ejecuta decisiones extranjeras, según su normativa de fuente interna?

Hay una diferencia importante entre el simple reconocimiento de una sentencia extranjera y su ejecución. En el primer caso, la sentencia se tiene por conocida y se le reconocen efectos extraterritoriales, en tanto que, en el segundo, además de reconocerla, se procede a su ejecución. Por ejemplo, puede reconocerse una sentencia extranjera que declaró culpable a una persona por homicidio, pero no se le reconocerá para efectos de ejecución, cuando esta es la pena de muerte.

He aquí otro ejemplo de simple reconocimiento: aunque pueda derivar de un asunto penal, la sentencia pronunciada en el extranjero podrá ser reconocida en México para efectos distintos de los estrictamente penales, como la estimación de la existencia de un delito que impida heredar. Otro ejemplo de simple reconocimiento se relaciona con la determinación de la reincidencia, caso en el que la sentencia extranjera podría reconocerse.

Quizá el más importante de los reconocimientos simples es el de la cosa juzgada; es decir, la norma según la cual nadie puede ser juzgado dos veces por el mismo delito, aun cuando la primera ocasión se hubiese sentenciado en el extranjero. Aunque esta norma generalmente funciona para problemas de tráfico jurídico interno, en el caso de una sentencia extranjera, los tribunales mexicanos también podrán reconocer la autoridad de cosa juzgada, aunque esta sea extranjera.
EJEMPLO: el CPF, admite que no podrá sancionarse penalmente ni aplicarle las leyes mexicanas a quien, habiendo cometido un delito en el extranjero, ya hubiese sido juzgado (artículo 4).

En materia de sentencia extranjera, un ejemplo así es el caso de una sentencia pronunciada en el extranjero en la que se hubiese impuesto una pena de reclusión, pena que ya se hubiese cumplido y ejecutado en otro país. Se trata de lo que Adolfo Miaja de la Muela denominó ejecución delegada. Este último caso parece ser uno de los más interesantes del derecho internacional penal.

La ejecución de una sentencia penal extranjera es tema relativamente novedoso en el derecho internacional. El primer tratado que sobre el particular se conoce en la época contemporánea surgió entre los países escandinavos en 1963. México modificó su artículo 18 constitucional para 
poder ejecutar sentencias extranjeras, lo que hasta antes de 1977 no era posible. No era posible que una sentencia penal extranjera pudiera producir efectos extraterritoriales a fin de ser ejecutada. Sin embargo, el criterio cambió y a partir de entonces en México se acepta reconocer las sentencias penales extranjeras y ser ejecutadas. No obstante, México, solo admiten dicho reconocimiento si es a través de un tratado internacional. El derecho de fuente interna nada dice.

México ha firmado varios tratados bilaterales que permiten que cada país signante ejecute la sentencia dictada en el otro país parte (verbigracia, Tratado sobre Traslado de Personas Condenadas para la Ejecución de Sentencias Penales entre México y Colombia).

En cuanto al órgano que ha de conocer una sentencia extranjera, en México tal facultad recae en el Fiscal General (acuerdo del Presidente de la República). Además, a diferencia de lo que ocurre en los procedimientos civiles, en los que un juez hace una serie de revisiones a lo largo del procedimiento de exequatur, en lo penal tal procedimiento no está regulado ni hay disposiciones respecto de los casos en que se pudiera rechazar una sentencia penal extranjera (carecemos de una regulación especial del procedimiento de exequátur y de resolución homologatoria). Las prescripciones de fuente interna son omisas en estos apartados.

Resulta de interés la cita a elementos del derecho convencional internacional, porque en este apartado el derecho de fuente interna aún es demasiado pobre. Poco es lo que se asienta en las leyes.

\section{RECONOCIMIENTO Y EJECUCIÓN DE MEDIDAS CAUTELARES Y DE OTRAS RESOLUCIONES}

Además del reconocimiento y ejecución de sentencias extranjeras, el orden jurídico mexicano acepta reconocer y ejecutar otro tipo de decisiones. La temática no se encuentra bien deslindada en el derecho de fuente interna, salvo algunos apartados excepcionales.

Tratándose de medidas cautelares, especialmente la reclusión preventiva, esta se impondrá en los casos de terrorismo internacional (previsto en los artículos 139 al 139 ter y terrorismo internacional previsto en los artículos 148 Bis al 148 quater del Código Penal) (artículo 167, frac. VI CNPP), disposición que proviene desde antes de las reformas penales de la actualidad.

Más novedosa es la disposición que dice que podrán reconocerse resoluciones extranjeras que ordenen un cateo. Así, podrá practicarse un cateo en buques, embarcaciones, aeronaves o cualquier medio de transporte extranjero en territorio mexicano y deberán observarse las prescripciones establecidas en las leyes mexicanas y tratados internacionales (artículo 287 CNPP).

En forma similar, es posible el reconocimiento de decisiones que ordenen el decomiso de bienes (artículo 452 CNPP). Como quiera que sea, es demasiado pobre esta reglamentación en las leyes mexicanas. 


\section{EXTRADICIÓN}

La extradición deriva de una solicitud de detención y entrega de una persona que ha sido acusada o condenada por cierto delito y que se encuentra en territorio extranjero. La petición se hace a un Estado requerido por un Estado requirente, según el caso. En el Estado requirente es donde esa persona fue acusada o condenada (Dondé Matute, Javier, Extradición y debido proceso, p. 56). La entrega es la extradición, y esta es el resultado de un proceso que sigue el juez requerido para determinar si procede entregar a la persona requerida, en cumplimiento de la solicitud de extradición realizada por el Estado requirente. No es mucho lo que el derecho de fuente interna establece, según las reformas habidas en los últimos años. Más bien, se trata de disposiciones fundadas en el derecho convencional internacional. Son dos los tipos de regulación de la extradición que se conocen: la que se logra con base en un tratado y la que se obtiene sin que exista ese acuerdo.

México cuenta con tratados bilaterales como multilaterales en materia de extradición. Celebró los primeros con Australia, Gran Bretaña, Bélgica, Belice, Brasil, Canadá, Colombia, Cuba, El Salvador, España, Estados Unidos de América, Guatemala, Italia, Países Bajos, Panamá y Nicaragua. El multilateral es la Convención sobre Extradición.

El derecho mexicano de fuente interna admite los dos medios. En México la extradición se regula tanto en el derecho de fuente interna como en el de fuente con- vencional internacional. Encontramos así algunos enunciados en el CNPP, al igual que en la vieja Ley de Extradición Internacional y, en el caso del derecho convencional, en dos tipos de tratados: bilaterales y multilaterales.

El orden jurídico de fuente interna se aplica ante la falta de un tratado entre los Estados requirente y requerido, de manera que prácticamente México puede acceder a solicitar la extradición de una persona a cualquier país, aun cuando no se hubiese suscrito un tratado con ese fin.

Dentro de las fuentes del derecho interno, el artículo 3 de la Ley de Extradición Internacional prescribe: "Las extradiciones que el gobierno mexicano solicite se regirán por los tratados vigentes, y a falta de éstos, por los arts. 5, 6, 15 y 16 de esta ley".

Por lo pronto, cabe tomar en cuenta que de acuerdo con el artículo 15 de la Constitución:

\begin{abstract}
No se autoriza la celebración de tratados para la extradición de reos políticos, ni para la de aquellos delincuentes del orden común que hayan tenido en el país donde cometieron el delito, la condición de esclavos; ni de convenios o tratados en virtud de los que se alteren los derechos humanos reconocidos por esta Constitución y en los tratados internacionales de los que el Estado Mexicano sea parte.
\end{abstract}

La Ley de Extradición Internacional regula los casos en los que México solicita una extradición a otro país (como Estado requirente), así como aquellos casos en 
que otro Estado le pide a México (como Estado requerido) que extradite a una persona.

Cuando México es requirente el orden jurídico mexicano resulta aplicable para tribunales locales (los de cada entidad federativa y los del Distrito Federal), así como para los federales. Según este orden jurídico, la solicitud de extradición al extranjero deberá tramitarse ante la Secretaría de Relaciones Exteriores, por conducto del más alto funcionario del Ministerio Público (MP).

Estas disposiciones de fuente interna prescriben los pasos que deben seguirse en México, no los que tienen que producirse en el extranjero, en donde normalmente se aplicará el orden jurídico del país en cuestión, salvo que exista un tratado de por medio.

Cuando el Estado mexicano actúa como requerido la reglamentación es más profusa. Así, se establece que pueden ser extraditables las personas que presuntamente cometieron un delito doloso o culposo. En el primer caso, la sanción en ambos países debe ameritar una reclusión de por lo menos un año; en el segundo, se requiere que la conducta sea sancionada con prisión en ambos países.

No procede la extradición en las hipótesis siguientes:

a) Cuando el reclamado haya sido absuelto, indultado o amnistiado.

b) Cuando falte la querella, si la ley mexicana la exige. c) Cuando haya prescrito la acción penal, según la ley mexicana o la extranjera.

d) Cuando no se trate de un perseguido político.

e) Cuando no se trate de mexicanos, salvo que la nacionalidad se hubiera obtenido después de los hechos que motivaron la solicitud de extradición.

Los tribunales mexicanos decidieron que sus autoridades no podrán revisar la constitucionalidad de una orden de aprehensión expedida en el extranjero y que haya dado lugar a la solicitud de extradición (AR 136/89, Manuel María Narváez y Méndez de Vigo, 28 de septiembre de 1989, registro: 226981). Se acoge, de esta forma, una tradición internacional que reza: "un juez no puede juzgar la justicia de una decisión extranjera". México condicionará la extradición por un conjunto de requisitos que el requirente tendrá que cumplir; por ejemplo:

a) Que el país solicitante sea recíproco.

b) Que el Estado requirente no proceda contra el extraditado por un delito distinto del que motivó la extradición, salvo que el extraditado así lo consienta.

c) Que el extraditado, una vez que proceda la extradición, sea sometido a un tribunal establecido ex profeso, en el que se le otorguen las garantías básicas de audiencia y de defensa, para lo cual deberán facilitársela todos los medios de defensa posibles. 
d) Que no se le imponga la pena de muerte o algunas de las prohibidas en el artículo 2 constitucional.

e) Que no sea re extraditado a un tercer país.

f) Que se envíe a México una copia de la sentencia que eventualmente se dicte.

El proceso de extradición podrá ser suspendido en caso de que el acusado tenga un juicio pendiente en México. La ley interna procura regular el procedimiento, entre otros aspectos, como la conformación de un sistema de preferencias para los casos en que una persona sea reclamada por varios Estados. En estos casos, el CNPP (artículo 141) prescribe:

El juez podrá dictar orden de reaprehensión en caso de que el Ministerio Público lo solicite para detener a un imputado cuya extradición a otro país hubiera dado lugar a la suspensión de un procedimiento penal, cuando en el Estado requirente el procedimiento para el cual fue extraditado haya concluido.

En un procedimiento de extradición el juez no decide en forma definitiva si una persona es o no extraditable, pues eso le compete a la Secretaría de Relaciones Exteriores (SRE), subordinando la decisión judicial a la política. El juez solo proporciona una opinión sobre el respeto del procedimiento y de las garantías, y esta opinión no compromete a dicha Secretaría. Es decir, el hecho de que el juez considere que se han respetado procedimientos y garantías no conduce necesariamente a que la Secretaría de Relaciones Exteriores (SER) deba proceder a la extradición. En el fondo, la última decisión es de naturaleza política, proposición que encuentra respaldada por la Suprema Corte de Justicia de la Nación (AR 6205/49, Depallens Paulsen Pablo y coag., 21 de octubre de 1950, registro: 299300):

De conformidad con el artículo 10 , fracción $\mathrm{V}$, de la Ley de Extradición Internacional, si el delito por el que se solicita la extradición es punible con la pena de muerte o alguna de las prohibidas por el artículo 22 de la Constitución Política de los Estados Unidos Mexicanos, acorde con las leyes de la parte requirente, la extradición no podrá concederse, a menos de que esta parte otorgue las seguridades suficientes de que aquéllas no se aplicarán, o que se impondrán las de menor gravedad que fije su legislación. En estas condiciones, si la pena de prisión vitalicia no es de las prohibidas por el referido precepto constitucional, es evidente que en los casos en que se solicite la extradición y el delito que se impute al reclamado sea punible en la legislación del Estado solicitante hasta con pena de prisión vitalicia, es innecesario exigirle que se comprometa a no imponerla o a aplicar una menor (Tribunal Pleno de la SCJN, aprobó, con el número 2/2006, la tesis jurisprudencial que antecede. registro: 175940).

\section{ASISTENCIA CONSULAR}

Una novedad en el derecho mexicano es la asistencia consular. Con base en 
el artículo 36 de la Convención de Viena sobre Relaciones Consulares, cuando una persona es detenida la autoridad que realiza la detención debe informar del hecho la oficina consular del país de donde el detenido es nacional (Corte Interamericana de Derechos Humanos, El Derecho a la Información).

Artículo 36. Con el fin de facilitar el ejercicio de las funciones consulares relacionadas con los nacionales del Estado que envía:

a) los funcionarios consulares podrán comunicarse libremente con los nacionales del Estado que envía y visitarlos. Los nacionales del Estado que envía deberán tener la misma libertad de comunicarse con los funcionarios consulares de ese Estado y de visitarlos;

b) si el interesado lo solicita, las autoridades competentes del Estado receptor deberán informar sin retraso alguno a la oficina consular competente en ese Estado cuando, en su circunscripción, un nacional del Estado que envía sea arrestado de cualquier forma, detenido o puesto en prisión preventiva. Cualquier comunicación dirigida a la oficina consular por la persona arrestada, detenida o puesta en prisión preventiva, le será asimismo transmitida sin demora por dichas autoridades, las cuales habrán de informar sin dilación a la persona interesada acerca de los derechos que se le reconocen en este apartado; c) los funcionarios consulares tendrán derecho a visitar al nacional del Estado que envía que se halle arrestado, detenido o en prisión preventiva, a conversar con él y a organizar su defensa ante los tribunales. Asimismo, tendrán derecho a visitar a todo nacional del Estado que envía que, en su circunscripción, se halle arrestado, detenido o preso en cumplimiento de una sentencia. Sin embargo, los funcionarios consulares se abstendrán de intervenir en favor del nacional detenido, cuando éste se oponga expresamente a ello.

En el polémico caso de Florence Cassez Crepin, la Suprema Corte de Justicia de la Nación (SCJN) explicó que:

La asistencia consular es vital para asegurar una defensa adecuada en situaciones que impliquen una privación de la libertad, en donde las violaciones a los derechos fundamentales de los extranjeros son comunes debido a la falta de conocimiento del sistema jurídico en el que se ven inmersos. Una persona extranjera que es detenida se enfrenta a una multitud de barreras lingüísticas, culturales y conceptuales que dificultan su habilidad para entender, de forma cabal y completa, los derechos que le asisten, así como la situación a la que se enfrenta (SCJN, Primera Sala, AD en revisión 517/2011, 23 de enero de 2013, resuelto por mayoría de votos, Florence Marie Louise Cassez Crepin, p. 97 de la sentencia). 
Conforme a la citada disposición y lo resuelto por la SCJN, además de la comunicación entre autoridades de diversos Estados, también existen garantías para que el detenido se contacte con sus autoridades consulares. La atención se pone en la nacionalidad del detenido, punto de conexión en torno del cual gira la disposición, pero no se alude únicamente al contacto del cónsul con su connacional, sino a la asistencia consular, punto que México ha defendido ante los tribunales internacionales. Al respecto, el artículo 113 del CNPP, fracc. XVIII prescribe: El imputado tendrá los siguientes derechos: "XVIII. A que se informe a la embajada o consulado que corresponda cuando sea detenido, y se le proporcione asistencia migratoria cuando tenga nacionalidad extranjera". Aquí cabe llamar la atención de que en los últimos años los tribunales federales han conocido más asuntos que involucran a la autoridad consular, que cualquiera otros relacionados con el derecho internacional.

\section{A su vez, el artículo 151 del CNPP pres- cribe:}

En el caso de que el detenido sea extranjero, se le hará saber sin demora y se le garantizará su derecho a recibir asistencia consular, por lo que se le permitirá comunicarse a las embajadas o consulados de los países respecto de los que sea nacional; el juez de control deberá notificar a las propias embajadas o consulados la detención de dicha persona, registrando constancia de ello.

El Ministerio Público y la Policía deberán informar a quien lo so- licite, previa identificación, si un extranjero está detenido y, en su caso, la autoridad a cuya disposición se encuentre y el motivo.

La SCJN ha definido la actividad del cónsul extranjero, diciendo:

[... no solo la asistencia del traductor y del defensor son suficientes para garantizar que el extranjero detenido enfrente el proceso penal en condiciones de igualdad procesal, pues también se requiere el apoyo de la oficina consular del país de origen para que desarrolle acciones de asistencia y protección, así como un acompañamiento con fines humanitarios. [...], el funcionario consular asume, además, la función de intérprete de las condiciones y circunstancias en las que se encuentra su connacional detenido, pues por existir afinidad cultural entre ambos, la intervención del cónsul le permite a la persona extranjera detenida comprender a cabalidad las consecuencias de sus decisiones en un contexto judicial ajeno a su realidad cultural y jurídica. [...]. Con la información traducida en contexto y proporcionada por el cónsul, la persona extranjera detenida puede ejercer su derecho a la defensa de manera plena, en condiciones de igualdad jurídica y material frente a la acusación que enfrenta por parte del Ministerio Público. Por tanto, es trascendental el carácter técnico de la asistencia consular a fin de determinar que sea real y efectiva. Lo que implica no solamente que se proporcione la asistencia jurídica mediante perito en derecho, sino que la efectividad de la defensa 
incluya elementos básicos de la tutela judicial a fin de preservar todos los derechos de defensa de la persona extranjera. [...]. Existen razones que permiten la disponibilidad del derecho por parte del extranjero, que se actualizan como por ejemplo cuando éste no quiere que su Estado se entere del lugar en que se encuentra por tener la condición de perseguido político. Circunstancia en la que entran en ponderación la protección de acceso efectivo a la justicia del Estado del que es extranjero el detenido y la protección de su vida, integridad física, libertad, etcétera, con motivo de la persecución de la que es objeto (AD 72/2012. 15 de mayo de 2013, registro: 2012048).

\section{CONCLUSIONES}

A pesar de que las autoridades mexicanas venían rigiéndose por el derecho convencional internacional, pocas eran las disposiciones de fuente interna que componían el orden jurídico mexicano regulando problemas de tráfico jurídico internacional, propios de asuntos penales.

En la investigación exploratoria la cuestión con la que se inició este trabajo consistió en conocer qué es lo que el nuevo orden jurídico procesal penal mexicano comprende, contrastándolo con lo habido con anterioridad, en especial, la recepción de los convenios internacionales incorporados al derecho de fuente interna.

Por ahora, una parte importante refiere a los derechos humanos, comenzando con la propia Constitución general, que impactan en la nueva codificación procesal que, a la vez, recibe diversos tratados internacionales.

En parte, la regulación deja de ser exclusivista para adoptar una posición de apertura, incluyendo la posibilidad de reconocer y ejecutar derecho extranjero, así como el reconocimiento de sentencias penales extranjeras.

En el ámbito de la competencia judicial, la ley de fuente interna incluye temas relacionados con la inmunidad diplomática y consular, así como propias de la universalidad de la jurisdicción.

Sobre cooperación entre autoridades, se incluyen disposiciones relacionadas con la solicitud de cooperación, así como para otorgarla. Aunque no se trata de enunciados profundos, cabe reconocer que se incluyen algunos. La Autoridad Central, ya conocida en asuntos civiles, familiares y comerciales, ahora se presenta en el ámbito penal.

Sobre extradición, el legislador prefirió dejar en vigor algunas leyes anteriores, pues poco es lo que se encuentra en la nueva codificación.

Lo que destaca con mayor fuerza es el apartado sobre asistencia consular a los procesados, seguramente por la decisión de la Corte Interamericana de Derechos humanos.

Es casi seguro que la inclusión de disposiciones de este tipo despertará estudios e investigaciones novedosas sobre esta temática. 
En general, la regulación de fuente interna mexicana, relacionada con los problemas de tráfico jurídico internacional ha sido escasa. No obstante, la nueva codificación ha acogido nuevas prescripciones, aunque insuficientes.

\section{REFERENCIAS}

Antonini, Mónica A., Ley de cooperación internacional en materia penal: la extradición y la opción, Buenos Aires: AD-HOC, 1998.

Bachmaier Winter, "Transnational Criminal Proceedings, Witness Evidence and Confrontation: Lessons from the ECtHR's Case Law", en Utrecht Law Review, Sep. 2013, vol. 9 núm. 4.

Cañardo, Hernando V, "La extradición, el delito político y el asilo extraterritorial a la luz de los principios del derecho internacional público", en Revista de Derecho. Publicación Arbitrada de la Universidad Católica del Uruguay, nov. 2013, vol. 8 .

Choclán Montalvo, J. A., "Delincuencia transfronteriza y equipos conjuntos de investigación", en Derecho Penal Supranacional y cooperación jurídica inter-nacional, Cuadernos de Derecho Judicial, núm. XIII, 2003.

Corte Interamericana de Derechos humanos, El Derecho a la Información Sobre la Asistencia Consular en el Marco de las Garantías del Debido Proceso Legal, Opinión Consultiva OC-16/99 de 1 de octubre de 1999.

Cuesta Arazamendi, José de la, "El proyecto de código penal internacional", en Revista de derecho público, núms. 92-93, 1983.

Diez Sánchez, Juan José, El derecho penal internacional (ámbito espacial de la ley penal), Madrid: Colex, 1990.
Dondé Matute, Javier, Cooperación internacional en materia penal, México: UNAM-Instituto de Investigaciones Jurídicas, 2013.

Dondé Matute, Javier, Extradición y debido proceso, México: Instituto Nacional de Ciencias Penales, 2011.

Miaja de la Muela, Adolfo, Derecho Internacional Privado, Madrid: Ediciones Atlas, 1985.

Paz y Puente, Jaime, Derecho de inmunidad diplomática, México: Trillas, 1985.

Récio Juárez, Matías, La expulsión de extranjeros en el proceso penal, Madrid: Dykinson. 2016.

Scarance Fernandes, Antonio y otros, Competência internacional do juiz nacional: estudo da extraterritorialidade da lei penal à luz do direito processual penal, Universidade de São Paulo, 2012.

Silva, Jorge Alberto, "La competencia judicial directa en materia penal ", en JUS. Órgano de difusión de la Escuela de Derecho de la U. A. C. J. Vol.7, mayo de 1989.

Silva, Jorge Alberto, Aplicación de normas conflictuales, México: Fontamara, 2010.

Silva, Jorge Alberto, Derecho internacional sobre el proceso, México: Porrúa, 2011.

Silva, Jorge Alberto, El caso Cutting, ¿Extraterritorialidad de la ley?, Juárez: Universidad Autónoma de Ciudad de Juárez, 2010.

Suprema Corte de Justicia de la Nación, Tratado de extradición, México: SCJN, 2000.

Suprema Corte de Justicia de la Nación. Semanario Judicial de la federación. 